\title{
Construction of College Service-oriented Student Working Model -Taking the example of Shandong Technology and Business University
}

\author{
Shiyang Li \\ Shandong Technology and Business University \\ Yantai, Shandong 264005
}

Keywords: College; service-oriented; student work

\begin{abstract}
The theoretical research of this paper includes: scientifically managing the dialectical relationship between education and management service through the innovation of working mode, strengthening the service efficiency and building service platforms, establishing long-term mechanism and promoting service efficiency, as well as enhancing the team construction and service level. After the analysis and research with the current service-oriented student working model construction in Shandong Technology and Business University, the following existing deficiencies were raised in this paper to provide new thoughts and opinions for the promotion of college service-oriented student working mode in Shandong Technology and Business University. Namely, related working ethic needs to be innovated, the content construction of students service platform requires to be improved, the operational mechanism needs to be professional, control mechanism requires to be promoted, and related security system needs to be perfected. The countermeasures and suggestions put forward in this paper give theoretical support for the college service-oriented student work on strengthening students service platform construction, improving regulations and working procedures, innovating service mechanism and enhancing service ability. Specifically, innovating the working concepts, strengthening the students service platform to make service efficiency more prominent, improving the regulation system and working procedures to standardize the service behavior, innovating the service system to promote service efficiency, and improving service ability to improve the incentive mechanism.
\end{abstract}

\section{Status Quo of Service-Oriented Students Working Model in Shandong Technology and Business University}

\subsection{Innovating the working model and scientifically manage the dialectical relationship between education and management service}

For a long term, college students work has neglected students' individual difference and principal status, and the training of principal awareness, causing the weakening education function, management authority and service quality of student work. In order to change traditional student working model and face the new situation, change and requirement of student work, our college specifically held the meeting for the whole-college student work, requiring to implement the work ethic of "students-oriented", strengthen the awareness of "service education" and put forward the establishment of student work service system which includes “graduates employment, enrollment, students' mental health education, student innovation and entrepreneurship, work-study program and student clubs and cultural activities, playing a positive role in talents training ${ }^{[1]}$.

\subsection{Strengthening the service efficiency and building service platforms}

Shandong Technology and Business University has regarded the high-quality service platform building as its carrier, constantly strengthened the construction of service-oriented student working model, and truly implemented the concept of "service education" and the function of "service students" into the daily work. In recent years, five service platforms particularly built by our school has made a progress. Specifically, the service platform of cultural learning activities, poverty-alleviation, employment, mental health education and student innovation and entrepreneurship ${ }^{[2]}$.

The service platform of cultural learning activities: We have carried out a series of campus cultural activities to make college truly help student cultivate their morality, intelligence and ambition, such as 
“Good Virtues Forum of Famous People”, "Report Directly in the Face of the Director”, “Alumni BBS”, the competition of college students' extracurricular academic science and technology works of "Challenge Cup", English speech contest, English vocabulary competition, mathematical modeling contest, experience sharing meeting of preparing postgraduates, debate contest of "new elites", class arena contest of "Harmonious Class and Charming Campus", as well as knowledge competition of class civilization and etiquette. The English tutor system for fresh students has been implemented, namely, selecting senior students who are good at English and of good compressive quality to act as fresh students' English tutors, developing extracurricular spoken English learning and training to improve their English practical application and overall quality, forming the three-dimensional platform with education tutors, political tutors and English tutors, in which students can achieve their own education, management and service. It has played an important role in the promotion of students' growth and development.

The service platform of poverty alleviation: We have established and improved the system for student financial aid to build a three-dimensional assistance system covering nearly 50 percent of students, including scholarship, grant, state financial aid, work-study aid, difficulty subsidy and tuition reduction.

The service platform of employment: In order to actively weather the difficult time of employment, we have completely implemented the project of "top leaders", established the virtuous recycling mechanism of "enrollment-cultivation-employment", and formed the employment pattern of "the party committeeled, functional departments-coordinated, all departments-dedicated as well as all teachers and studentsparticipated". The strategy of "going out and opening-up" has been adopted to truly strengthen the communication and cooperation with government personnel departments, local talent markets and enterprises, integrate diversified resources, and expand the job market for graduates. In order to promote students' working abilities, we have employed professional trainers, well-known alumni and specialized teachers to make different career planning and employment guidance for the students at different study stages in the form of presentations, special lectures, seminars and corporate BBS. We will effectively strengthen graduates' ideological and political education, and actively guide them to work at the grassroots level, western regions and those places where the motherland is most in need. In the past two years, the employment rate in our school still remained above 90 percent under the extremely severe employment situation.

The service platform of psychological health education: It has perfected the working mechanism of psychological crisis intervention, mental treating, psychological evaluation and mental health track investigation. Form a psychological counseling team oriented with professional teachers, make it clear all the related teachers every department and invite domestic famous psychological health experts to teach our counselor teachers.

Service platform of student innovation and entrepreneurship: Our college invests the innovation and entrepreneurship every year to give a rolling support for college students to carry out this activity. "Innovative experiment plan for college students" has been established to encourage college students to develop scientific research and entrepreneurship experiment. The plan of college students as rural officer has been hard pushed to encourage and guide graduates to work in the countryside and have their own business in the basic level. College students are helped to establish entrepreneurship awareness and master the necessary knowledge and abilities by means of entrepreneurship forums and lectures.

\subsection{Establishing long-term mechanism and promoting service efficiency}

In order to improve the service quality and level of student work, out college has kept the innovation inside and the reference outside and positively constructed the long-term mechanism for service-oriented student work model.

Build and perfect the positive guidance mechanism for students' overall development. Students are correctly guided by the ideological guidance, learning tutoring, education and typical example.

Build and perfect the communication mechanism between teachers and students to solve the problem of students' overall development. It has established the system of department leaders accepting students' interview, having a relation with students' classes and genuine talking, which can strengthen the 
communication with students, specifically educate and guide them and deal with the real difficulties and problems in their ideology, learning and life.

Perfect and improve the diversified incentive mechanism to speed up the overall development of students.

Establish and perfect the mechanism of students' problem feedback and deadline solving to provide guarantee for their growth and development ${ }^{[3]}$.

\subsection{Enhancing the team construction and service level}

The key point is to improve the service ability of student cadres so as to further strengthen the construction of student cadres team and improve the professional service level. We should carefully implement the related regulations and requirements of Counselor Team Construction Regulations in Common Colleges and Universities to establish a solitary and strong counselor team with firm politics, appropriate number, rational structure, professional business, excellent quality and high efficiency, as well as strengthen their learning training and outward communication.

\section{Current Existing Deficiencies of Service-Oriented Students Working Mode in Shandong Technology and Business University}

The work ethic of service-oriented students needs to be innovated. Most students cadre and related functional departments have established the firm concept oriented with students since our school built the service-oriented students working model. But all the teaching staff should promote their cultivation concept, strengthen the democratic and legal idea, as well as keep and develop the working ethic of "everything is for students, for everything of students and for all the students".

The content construction of students service platform requires the further improvement. Five service platforms that our college particularly built has made a progress, including the service platform of cultural learning activities, poverty alleviation, employment, psychological health education and students' innovation and entrepreneurship. However, the service platform construction of students' life, career planning and development and legal rights needs to be further improved.

Its operation mechanism needs to be professional. The college is supposed to positively construct the long-term effective operational mechanism of service-oriented students work and form the service center of students' affair to provide professional service platforms for students. For instance, college students' growth and development center, learning support center, academic and research guidance center, career development and employment guidance center, psychological development consultancy and education center, student aid center, campus activity guidance center, as well as the service center of legal aid, student health, and logistics.

The related security system needs to be improved. Diversified regulations and rules should be further perfected from the perspective of system security, for example, Provisional Regulations on Student Scholarships in Shandong Technology and Business University, Measures for Implementing the Selection of Social Grant-aid and Scholarship in Shandong Technology and Business University (trial implementation), and Measures for Implementing the Identification of Students with Financial Difficulties in Shandong Technology and Business University (trial implementation). In order to provide guidance and service for students' learning and life, administrative approval systems and working regulations should be further standardized, such as publishing Student Affairs Service Guide in Shandong Technology and Business University. In the terms of staff security, increase the allocation of full-time counselor (according to the equipment of 1:200 of strengthening the college tutor and head teacher construction in general) to guarantee every grade of every college (department) has some full-time instructors, as well as establish the diversified training institutions, overall planning and rational flow to keep the dynamic balance of students affairs team. From the aspect of material security, guarantee the fund investment of students work, strengthen the construction of students' playing field and facilities and promote the campus network of students' apartment. On environmental protection, positively strengthen and construct 
the three-dimensional education environment of family, society and college to optimize the surrounding environment of campus.

Its control mechanism needs to be further improved. It mainly includes the five aspects in our college, namely, the mechanism of scientific warning, effective supervision, reasonable evaluation, timely feedback and sound encouragement.

\section{Countermeasures to Promote Service-Oriented Students Working Model in Shandong Technology and Business University}

\subsection{Promoting the innovation of service-oriented students work ethic in Shandong Technology and Business University}

Promote the concept of people-oriented. Service-oriented student working model must be more human, and the basic target of student management should be serving, respecting, caring for, training and motivating students, and promoting their overall development surrounding their growth and success.

Strengthen the democratic concept. Democracy is presumed for equality, reflecting the principle of human value pursuit. It's contained rules and principles are universally adopted in college student management, such as freedom and equity, and the unification of rights and obligations.

Establish the legal concept. In the student management, it means fully respecting and protecting college students' legal rights.

\subsection{Strengthening the students service platform to make service efficiency more prominent}

Service platform construction of innovative cultural learning activities. Develop the theme culture study with the style of study as its core, class construction as the foundation and quality development as its emphasis.

Strengthen the service platform of poverty alleviation. We should carefully implement the related policies of national new funding policy and system to enlarge the college student aid work. Establish and improve the three-dimensioned funding system combined with scholarship, state loans, work-study aid, assistance for the poor, tuition reduction and exemption, fully playing a role in helping and motivating.

Make efforts to strengthen the service platform construction of psychological health education. We should make more work on students' mental health education and consultation to increase the intervention with their psychological crisis.

Focus on promoting the service platform construction of student innovation and entrepreneurship.

Constantly innovate the information service platform construction.

Exactly improve the platform construction where students can realize their own education, management and service.

\subsection{Improving the regulation system and working procedures to standardize the service behavior}

3.3.1 Further establish and perfect various rules and regulations of student work.

On the basis of the reality, we have revised the Provisional Regulations on Student Scholarships in Shandong Technology and Business University and Work-study Management Measures in Shandong Technology and Business University, and these regulations about student management can make the system more human, scientific, standard, practical and operative.

We have issued the National Student Loan Management Measures in Shandong Technology and Business University (trial implementation), Work-study Base Management Measures in Shandong Technology and Business University (trial implementation), Measures for Implementing the Identification of Students with Financial Difficulties in Shandong Technology and Business University (trial implementation), so as to standardize the identification work of students in the face of these problems.

Our college has formulated the Measures for National Scholarship, Encouragement Scholarship, National Financial Aid Award Implemented in Shandong Technology and Business University (trial implementation), Measures for Selecting Demonstration Class, Advanced Class, Merit Student Model, Merit Student and Outstanding Student Cadre in Shandong Technology and Business University (trial implementation), and Measures for Implementing the Selection of Social Grant-aid and Scholarship in 
Shandong Technology and Business University (trial implementation), which can further standardize the award and evaluation process, and strengthen the standardization and operability.

3.3.2 Make a further step to standardize the administrative approval system and working procedures.

Simplify student working procedures and reduce intermediate links to improve administrative approval efficiency.

All working procedures are published prominently in the "student work online" and the student activity center. Teachers and students have an access to download the related approval excels at the "student work online".

Print and copy the Student Affairs Service Guide in Shandong Technology and Business University to provide learning life guidance and service for students.

\subsection{Innovating the service system to promote service efficiency}

We will establish and improve an open, fair and impartial reviewing and management mechanism for student awards, merit evaluation, party membership, and funding to ensure that they have full rights to know and participate in what is concerned with their interests, and increase the transparency.

Establish and improve an effective communication mechanism between teachers and students.

Establish and improve the mechanism for student problem feedback and deadline solving. The department (office) of student work should timely research and solve the problem students reflect through various channels. Then they should raise the solving schemes (if related to other departments, timely coordinate and communicate with the relevant functional departments), and timely make a feedback to students with the solving result by means of writing or oral reply.

Improve the assessment and evaluation mechanism of the property management and service level in students' dormitories. Strengthen the communication and coordination with logistics and property and establish a service mechanism to protect students' basic interests. Students' satisfaction with property management service plays an important role in assessing the property management, which can help to supervise the logistics and property management improve their management service level.

\subsection{Improving service ability to improve the incentive mechanism}

We have put forward new tasks and requirements for student cadre and adopted new countermeasures to enhance the whole quality of student cadre according to the new situation of higher education development. Also, our college has formulated the Work Regulations for Counselors in Shandong Technology and Business University (trial implementation) on the basis of researching the Provisions on the Counselors Construction in Ordinary Colleges and Universities (Decree No. 24 of Ministry of Education), in order to standardize the counselor recruitment, management, training, praising and punishing, as well as strengthen the team construction of counselors.

Establish the assessment system for college student work service efficiency.

Strengthen the study and training of student cadres.

Strengthen the research on the theory of student work. We will encourage and support student cadres to carry out the theoretical research and practical exploration on student work surrounding the hot and difficult issues in student work, and organize major power to carry out related research. We have printed and copied the Student Work Essays in Shandong Technology and Business University, and formulated the Measures for Student Work and Scientific Research Reward in Shandong Technology and Business University (trial implementation), to reward the theoretical research result of student cadres in different levels.

\section{Conclusions}

The essence of the college service-oriented student work mode is "student-oriented", starting from students' fundamental interests, respecting, caring for, serving, educating, guiding , promoting and developing students. Namely, students should be the basic part of student work, which should conform to their talents, improve their potential, most widely mobile their positive factors, most fully stimulate their creativity, give full play to their subjective initiative, greatly educate and guide them, as well as help their 
complete and overall development. In a word, this model is always regarding students' overall development as the starting point and ultimate end. This model, constructed under the education service concept of "Scientific Outlook on Development", sees students' characteristics and demands as the starting and ending point. The principal part of implementation is all teachers and students in the college. Among them, student workers are the "protector of students' interests, representative of students' thinking and assistant of students' success". They have explained the related work content with the core value orientation of "service". Existing problems in the current college student work system is the lack of student-oriented concept, blocked organization and operational mechanism, and not enough team guarantee. Its successful operation cannot leave the corresponding mechanism to "strengthen" and "consolidate”. The operational mechanism system includes: leading mechanism, operational mechanism, ensuring mechanism and controlling mechanism. The operational mechanism is under unified leading of college party committee, comprehensively responsible by the director, jointly supervised by the party and league, respectively charged by the functional department and service center, jointly assumed by all staff and specifically responsible by student workers. The countermeasures and suggestions put forward in this paper give theoretical support for the college service-oriented student work on strengthening students service platform construction, improving regulations and working procedures, innovating service mechanism and enhancing service ability. Specifically, make strenuous efforts to innovate the working concepts, strengthen the students service platform to make service efficiency more prominent, improve the regulation system and working procedures to standardize the service behavior, innovate the service system to promote service efficiency, and improve service ability to improve the incentive mechanism.

\section{References}

[1] Zhu Yixin. The application of humanistic management thought in the management of college students[J]. Journal of East China Shipbuilding Institute, 2001(3).

[2] Zhao Pengfei. Exploration of the college students management model in the new era[J]. China Women's University, 2002(5).

[3] Zhao Haitao. Innovation of college student work under the new situation[J]. China Adult Education, 2008(9) 